\title{
The effects of leadership on safety outcomes: The mediating roles of trust and
}

\section{safety climate}

\begin{abstract}
:
Background: In the current study, the mediating roles of safety climate and trust in the relations between leadership styles which are transformational and transactional and safety outcomes which are safety compliance and safety participation are studied. Methods and Material: 101 blue-collar workers from a company in Zonguldak were participated in the study. Results: The results showed that transactional leadership is strongly associated with safety climate. As predicted, transformational leadership is found to be significantly correlated with safety participation. Conclusions: Moreover, transactional leadership is strongly correlated with safety compliance. Both safety climate and trust showed significant correlation with both of the safety outcomes. The mediating roles of trust and safety climate within the relations between transactional leadership and safety compliance and transformational leadership and safety participation are also found.
\end{abstract}

Key Words: Leadership, trust, safety climate, safety outcome

Reyhan Bilgiç, Merve Betül Bulazar, Elif Bürümlü, İbrahim Öztürk, and Ceyda Tașçığlu

Department of Psychology, Faculty of Arts and Sciences, Middle East Technical University

Corresponding Author: Dr. Merve Betül Bulazar Email: e179113@metu.edu.tr

○ 2016 IJOSH All rights reserved.

\section{Introduction}

The Every year from different industries many accidents and deaths were reported in many countries. According to International Labor Organizaiton reports (2012), evey 15 second a worker dies and 153 workers have work related accidents. Moreover, according to the same report, 317 million work place accidents and 2.3 million workplace deaths occur every year, corresponding to 6.300 deaths per day. in Turkey, last decade 13000 people were killed and 24500 were injured and disabled due to accidents. The last year alone, 1886 people died due to accidents according to Eurostats as cited by daily news of Turkey. According to the Statistical Institution of Turkey (TUIK, 2013) reports, within a year, those who are employed, $2.3 \%$ had will have work accidents. These numbers surmount when all countries were included. Therefore workplace safety became a number one policy issue all over the world especially for the safety critical organizations. These organizations are construction, coal mining, military and the like where performing safe work is primary concerns and considered to be major work stress (Nielsen, Mearns, Matthiesen, Berg \& Jarle, 2011).

Occupational Safety and Health Administration of United States (OSHA) remarks the importance of workplace safety and health that decreases injuries and fatalities. Improving safety not only will reduce deaths and injuries but also will alleviate cost to train replacement employees, and rise productivity and financial performance (OSHA, n.d.). Moreover, in Turkey, a specific department of workplace safety was established by Turkish Ministry of Labor and Social Security. Some responsibilities of this department are listed as making research about risk factors of workplaces in terms of health and safety; planning the activities of risk evaluation in workplace and taking precautions for occupational diseases and injuries at work and so on. (ISGUM, n.d.). For these reasons, wide range of studies conducted to examine factors that contribute to improvement of safety conditions and safety related outcomes. One of these factors might be related to workplace equipment. There are many studies related to these factors. For example, more recently in Hong Kong, to reduce injuries among construction workers, a feasibility research for safety helmets' chin straps was conducted and chin straps was suggested as a legal necessity for construction workers in Hong Kong (Fung, Lee, Tam, \& Fung, 2014).

What other factors might have influence on safety is a question tacled by many researchers and their studies One of these studies divided factors that affect safety performance on construction sites into seven groups that are historical (background and characteristics of individual), economical (safety issues related to money like hazard pay), technical 
(awareness of the hazardous materials), procedural (training about safety equipment), psychological (personal care for own safety and perception of their supervisor's safety attitude), organizational and the working environment (organization's attitude toward safety issue). Results revealed that among all these factors, organization's safety attitude was found to be the most significant element for construction workers' safety related behaviors (Sawacha, Naoum, \& Fong, 1999). In a same vain, Graven \& O'Brien (2001) pointed out that among all the factors listed related to workplace accidents and injuries, studies are pointing out the fact that accidents occurring in work places may be due to the human acts which may be controllable. Similarly, the study examining the causes of injuries in a manufacturing industry pointed out that rather than active causes such as workplace conditions, installation and machinery, latent factors such as safety management, training, personal characteristics of workers, and safety activities play important role in accidents and safety problems at work (Carrillo- Castrillo, Rubio- Romero, \& Onieva, 2013). Therefore, it is necessary to examine these factors.

Some studies focused on the importance of of leadership styles on safety outcomes. Especially transformational and transactional leadership styles were widely associated with safety outcomes (e.g., Kelloway, Mullen, \& Francis, 2006; Zohar \& Luria, 2010). Additionally, trust is another important factor that is mostly related to organizational outcomes such as commitment to the organization as well as safety outcomes such as accidents. Basically, in literature Interpersonal trust that is between employees and their managers in an organizational environment has been described as "as the individuals' belief in willingness to act on the words, actions and behavior" (McAllister, 1995, p. 25). Based on this definition, many research pointed out the important role of employee's trust to the leader on their safety- specific behaviors. For instance, Luria (2010) found that as the level of trust to the leader increase, injury rate decreases, whereas perceived level and strength of safety climate in organization rises.

In addition to these factors, researchers investigated some other variables closely associated with safety outcomes in the organizations such as safety climate. The term "safety climate" first introduced by Zohar (1980) defined as employee's collective perceptions related to their organization's and their leaders' attitude toward safety. In the meta-analytic study that examined the association between safety climate and safety related behaviors (safety participation and safety compliance) stated that organization's safety climate is more likely to affect employees' safety participation and safety compliance. In other respects, the moderated effects of study design on the relatedness between accident inclusion and safety climate was stated (Clarke, 2006). What other factors might effect safety, safety related issues are studied. It was mostly found that type of leadership and trust in the leader might also effect the safey at work, (see . Clark, 2013)

In the present study, our aim is to show the leadership styles' impacts on safety outcomes (safety participation and compliance) with the mediating effects of safety climate and employee's trust in leader's concern for safety. In the literature, there are some studies that examined safety climate's influence as a moderator or mediator on the connection between leadership and safety related behaviors (Clarke, 2013; Kapp, 2012). On the other hand, trust was investigated separately with leadership and safety issues (Conchie \& Donald, 2008; Zhu, Newman, Miao \& Hooke, 2013). Our study will make a further contribution by adding trust as a mediator to the association between leadership and safety outcomes.

\section{Leadership Styles}

Recently, to reduce workplace safety injuries and improve employee's safety performance, researchers have focused on leadership styles as key factors. For that reason, different types of leadership styles' have been investigated in terms of their influence on safety related outcomes (Cavazotte, Duarte, \& Gobbo, Clarke, 2013; Mullen, Kelloway \& Teed,2011, 2013; Nielsen, Eid, Mearns, \& Larsson, 2013). Especially it can be seen that transformational and transactional leadership styles have been widely discussed in terms of safety outcomes in the literature (Clarke, 2013).

Transactional leadership is defined by Bass (1985) as leaders who clarify both the needs of organization and appropriate steps to reach the specific goal. Then, they share the idea that meeting the organizational goal will also fulfill employees' individual needs by means of rewards. Transactional leadership, formally, includes four specific styles that are contingent reward, management- by- exception active (MBEA), management-byexception passive (MBEP) and laissez- faire. In contingent reward style, leader both establishes some organizational goals and rewards for employees. While explaining the appropriate steps needed to meet these goals, they reward their followers depending on fulfilling these goals. In relation to safety, leaders with contingent reward style clarify safety- specific goals to their employees, follow their actions and provide them rewards to facilitate the fulfillment of safety- specific goal (Hoffmeister, 2012). In management- by- exception active MBEA style, leaders have a tendency to follow their employee's behaviors and intervene with corrective actions before any serious problem take place. Similarly, leaders with management-by-exception passive MBEP style also try to monitor their employee's behaviors; however, they make an intervention when the problem takes place. Finally, laissez- faire leaders are defined as absent or disorganized leaders who don't engage in their 
employees' work (Bass, 1985). In the present study, MBEA and MBEP forms will be aggregated.

Transformational leadership was explained by Bass (1985) in regard to three points. Firstly, transformational leaders enhance their employees' awareness of task importance and value. Therefore, the workers might espouse higher safety values. Secondly, they help their employees to value first team or organizational goals above their own interests. If the primary goal of the organization is safe work, employees will also value this due to their transformational leaders. Lastly, they give importance to activate their followers' higher- order needs. For example if they are motivated by tangible aspects of the work place they may be motivated by higher order needs. Moreover, Bass also ground transformational leadership on four components that are idealized influence, inspirational motivation. Idealized influence is related to leaders' behaviors and attributes that build employees' feelings of trust, integrity and confidence to them. Their desired behaviors serve as a role model for the employees, which contributes to identification of employees with the leader. Therefore, followers with the transformational leaders will trust their leader and be emotionally connected. This will make them more committed to the values and goals of organization. As a second component, inspirational motivation is defined as leader's effort to determine a vision attractive for employees and to inspire them toward their goals. For example, a leader may articulate how the the future of the organization will be with the safety procedures administered. Those leaders are willing to provide meaning about the safety goals and to make employees optimistic and enthusiastic about future goals. Another component of transformational leadership is intellectual stimulation. Leaders who intellectually stimulate the employees take risks and focus on activation of employees ideas. They encourage employees to be creative and to look for new perspectives to solve the old problem with the invented techniques. The last component is individualized consideration. Leaders with this dimension put more emphasis on their employees' needs and individual differences among their employees, they give importance to their employees' personal and professional development. Therefore, they behave as a mentor or coach to help followers to reach their full potential (Bass, 1985). As any other leadership style, this type of leadership style also have some consequences for both organization and employees.

Leaders influence their employee's behaviors by setting the positive tone in the work group according to the study of Wu and Wang (2015). In turn, this positiveness will make people proactive in solving their problems. Since safety behaviors and safety climate are important issues for the safety critical organizations, employees proactive behavior will be directed to safety as the most important outcome of leadership in highly safety critical organizations.

\section{Leadership style, safety climate and safety outcomes}

Safety behaviors, safety participation and compliance, and safety climate and culture are important safety outcomes in safety critical organizations. For example the search for leadership and safety from data bases, the present researchers found that the most frequently cited leadership styles are transformational and transactional leadership styles. The reason behind these types of leadership is that they both related to employee behavior and these styles seem to be the most fundamental ones due to the fact that their dimensions contains almost all of the leadership styles studied so far. For example, the transactional style includes behavioral aspect of leadership such as initiating structure, path goal and expectancy theory in addition to lasses-fair type of leadership. On the other hand transformational leadership may involve in some way leader-member Exchange (see for example: Zacher, Pearce, Rooney, \& McKenna, 2014), ethical leadership and similar leadership styles (Öncüoğlu, 2013).

The reason as to why transformational and transactional styles of leadership is related to safety outcomes is the fact that they either reward, set goals or change the aspiration level of employees and general attitudes towards safety which is the most important outcome in safety critical organizations. In terms of safety outcomes, the studies found that transactional and transformational leadership styles were associated with decreased injury rate and greater safety climate in the organizations (Zohar, 2002).Transactional leaders affect the safety related behaviors of employees by monitoring and setting goals and they use reinforcement to increase safety behaviors (Flin, \& Yule, 2004; Griffin, \& Hu, 2013).

Although transactional leaders use monitoring and setting goals, transformational leaders use four different elements to motive safety related behaviors of their employees. Transformational leadership is generally studied as general leadership style. However, Barling, Loughlin, and Kelloway (2002) studied safety specific transformational leadership style. This style shows same characteristics of transformational leadership. Furthermore, Mullen and Kelloway (2009) indicated that transformational leaders affect and change attitudes and behaviors of employees towards safety issues by inspiring them (Barling et al., 2002; Innes, Turner, Barling, \& Stride, 2010). On the scope of safety, leaders with idealized influence try to increase employees' awareness of safety related issues by expressing safe behaviors. Inspirational motivator leaders support and promote employees to reach goals related to safety outcomes (Clarke, 2013). Furthermore, leaders with high intellectually stimulation are expected to direct their employees to find new and innovative solutions for safety- related problems. Finally, leaders individually considering their followers care about their employee's safety and wellbeing (Glendan, Clarke, \& McKenna, 2006).

In the literature, safety complience and safety participation used as two of the most important outcomes of safety as related to leadership style. Safety compliance is related to the fact that employees abide by the rules of safety with the expectations that their goals related to safety will be achieved. This is more or less safety behavior. Safety compliance is defined as the 
behaviors that are done for the individual workplace safety by obeying rules and wearing personal equipment. On the other hand, safety participation refers to the fact that individual tries to find ways of improving safety environment and safety performance of the organizations (Fugas, Meliá, \& Silva, 2011). The safety participation includes the behaviors that help to increase environmental safety rather that individual level (Neal, \& Griffin, 2006). To base such assertion, the empirical literature was investigated. Studies show that transformational and transactional leadership styles affect both safety compliance and safety participation of employees. In the study of Innes et al. (2010), found that transformational leader is associated with safety participation. Because of the general promoting style of transformational leaders, employees are more willing to be a part of safe work environment.By the same token, Griffin and $\mathrm{Hu}$ (2013) found that safety monitoring behaviors which is related to transactional leadership results in safety compliance and safety inspiring behaviors related to transformational leadership result in safety participation. In the same vein, Clarke (2012) found that safety participation is correlated with transformation leadership whereas safety compliance is correlated with transactional leadership. Transactional leadership especially the MBEA part will be related to the in-role safety behavior, which is related to monitoring subordinates' behaviours, anticipating problems and taking proactive steps to implement corrective actions. This is related to employee behavior (in this case safety compliance). When we ask why transformational leadership leads to safety participation is because, transformational leadership is relate to safety climate since climate is related to perceptions and transformational leadership provides array of perceptions on the part employees not the actual behavior. Thus, Transformational leadership and its aspects will motivate employees to perform extra role safety performance namely safety participation. Therefore,

Hypothesis 1: Transformational leadership style is strongly related to safety participation,

Hypothesis 2: whereas transactional leadership is strongly related to safety compliance.

Safety climate is also important for the safety outcomes in the organizations. Organizational climate refers to the total perception of the individuals in an organization (James \& James, 1989). It has both individual and group level. In the present study, climate will refer to the individual level perceptions. There are many forms of organizational climate such as safety, ethical, service, and innovation. Safety climate refers to the perceptions of employees about safety procedures and processes of organizations. Zohar (1980) found that safety climate has different dimensions. In general, safety climate includes perceived attitudes and behaviors of managers about safety, effects of expressing safe behaviors towards promotion, social status, safety training, and perceived risk level in the organization.. All of these shape the safety climate of the organization. Safety climate of the organization affects safety related events and safety outcomes of the employees.
Giving importance to safety outcomes will increase the safety climate in the organization (Barling et al., 2002).

Hypothesis 3: Perceived safety climate predicts both safety participation and safety compliance.

\section{Leadership style, trust and safety outcomes}

Although there is a great interest and many research about organizational safety and outcomes, fewer research focus on the formation of safety climate in organizations. One of these studies made an effort to conceptualize safety climate at the individual level; and revealed that trust is a significant characteristic of management in the formation of safety climate as a psychological process (Shen, Tuuli, Xia, Koh, \& Rowlinson, 2015). Building the framework of trust to the leader is important to determine behavioral and attitudinal markers of organizational safety outcomes. Trust can be thought as a key factor in the formation of social order, indicates positive expectations about others' intentions and behavior and affects interdependence of different roles in an organization, whereas safety-specific trust to the leader is defined as the perceptions of employees about their leader's safety values and behaviors (Tharaldsen, Mearns, and Knudsen, 2010). Research on trust has widely been conducted and associated with positive organizational outcomes (Seppänen, Blomqvist, \& Sundqvist, 2007), higher organizational performance (Conchie, \& Donald, 2006), and positive effects on safety culture and safety performance (Burns et al, 2006; Conchie, \& Donald 2008). For example, the psychological constructs of safety behavior has been investigated. It was found that trust as a psychological mechanism behind safety performance supports communication and interaction between managers and employees. Moreover, it increases their motivation and intentions to act in a safe manner (Larrson, \& Turner, 2008; Törner, 2011). Similarly, interpersonal trust in organization is necessary for caring about safety that managers have to gain the trust of employees and also behave respectfully to them (Ferjencik, \& Slovackova, 2014). Furthermore, higher level of trust significantly predicts positive safety outcomes (Luria, 2010). Clearly, we can conclude that perceptions of trust in organizations influence safety behavior and safety related outcomes. That is, the exposure to accident (safety performance) resulting from safety behaviors (safety compliance and safety participation) are significantly related to trust (Tharaldsen, Mearns, \& Knudsen, 2010). In our study, trust is operationally defined as a level of trust of employees' to their leaders' commitment to safety related issues.

Hypothesis 4. There will be significant effects of trust on safety outcome, such as safety behaviors.

It is important to find out the type of leaders who instill trust in their employees. Among leadership styles, transformational and transactional leadership styles build higher level of employees' trust (Jung, \& Avolio, 2000; Krafft, Engelbrecht, \& Theron, 2004). By expressing interest and respect for employees, transformational leaders gain their employees' trust (Jung, \& Avolio, 2000). Furthermore, transformational leaders instill trust 
especially cognitive based trust in their employees and this cognitive based trust is important for performance (Schaubroeck, Lam \& Peng, 2011). In literature, trust also has a significant impact on the leaders and employees' attitudes (Dirks \& Ferrin, 2002). For example, Braun, Peus, Weisweiler and Frey used mediation effect of trust in their study about leadership and job satisfaction and team performance (2013). Moreover, YI-Feng Yang also revealed that trust has an important role on the relationship between transformational leadership and job satisfaction (2014). Therefore, both transformational and transactional leadership will have impact on trust, but the effect of transformational leader will be stronger than transactional leadership.

Hypothesis 5: Transformational leadership will be strongly associated with trust to leaders' commitment to safety than transactional leadership.

\section{Effects of Transactional and transformational leadership styles on safety climate.}

Studies show that leadership characteristics are important antecedents of climate (Zohar \& Luria, 2004) and most important leadership style is transformational leadership (Christian, Bradley, Wallace, \& Burke, 2009; Nahrgang, Morgeson, \& Hofmann, 2006). Clarke (2013) pointed out that both trasformational and transactional leadership are strongly related to safety climate. And this relationship is tronger fort he transactional leadership active management type. However, Hoffmeister; Gibbons, Johnson,; Cigularov, Chen, \& Rosecrance, ( 2014) pointed out that active management part of transactional style has olmost no relationship with safety climate. Therefore, to resolve the relationship, reasrch question will be asked. Does trasnactional leadership has influence on safety climate as well as the transformational style on safety climate.

\section{Mediating effects of safety climate and trust on safety outcomes}

In the study of Clarke, she developed a model that includes perceived safety climate as a mediator in the relationship between leadership styles and safety outcomes (2013). However, in the literature, studies examining the relationship between leadership styles and safety outcomes rarely use trust as a mediator in the relationship model. In this study, we aim to develop a hypothesized model that includes trust and safety climate as a mediator in the relationship between leadership styles and safety outcomes.

Hypothesis 6. Transformational leadership style is positively correlated with safety participation with respect to mediating effects of safety climate and trust in leaders' commitment to safety. Transactional is associated with safety compliance with respect to mediating effects of safety climate and trust in leaders' commitment to safety
Figure 1 Hypothesized model of leadership, safety climate, trust, safety outcomes.

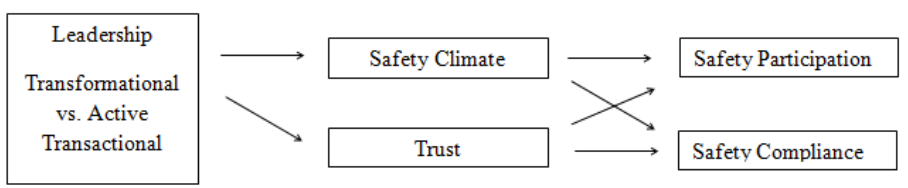

\section{Methods}

\section{Participants}

A hundred and one people working in the different departments of a manufacturing plant located in northern part of the country participated in the present study. The mean age is 32 with a 5.8 standard deviation. Of the participants, $94 \%$ were male and $6 \%$ of the participants were female. Fifty percent the participant were graduated from high school and $69 \%$ of them were currently working in the departments related to production such as manufacturing, metal, and molding room and $31 \%$ of the participants were working in the other departments such as delivery, packing, and store. All the departments involved some degree of safety risk, hovever, it was more so on the production department.

In the current study, the survey consists of five questionnaires which are leadership questionnaire (Dönmez, 2014), Safety Climate Scale (Zohar, 1980), Safety Outcome Scale (Neal, Griffin, \& Hart, 2000), Trust Scale, and Demographic Information.

\section{Leadership Questionnaire.}

The leadership questionnaire is developed by Seval Donmez (2014) to measure transformational and transactional leadership. In this study, 17 items from original study was used. These items were chosen to represent each characteristic of transformational and transactional leadership styles. Of them, six items were designed to measure transactional leadership style while 11 items were related to transformational style. The survey consists of 5 point Likert-Type from totally disagree to totally agree. These items measure employees perception of their leadership style and relations with their leaders. Example items for the transformational part of the questionnaire are "My leader encourages me to take initiatives." and "My manager plans trainings for my deficient aspects." The transactional items included such statementas like "the relation between my leader and me is like transactions", and "if I did not perform what my manager asks, I may be enforced to do so".

\section{Safety Climate Scale.}

This scale is develop by Zohar (1980). The current Turkısh translation of the scale is done by Harika Yücebilgiç (2007). The Safety Climate Scale consists of four subscales with 40 items. Items are 5 Likert-type from totally disagree to totally agree. Reliability of the scales ranged from .51 to .90 in Yücebilgiç's study. In the current study, 12 items from the scale is used. Items are chosen to equally represent each of the subscale. Example items are "There is a high probability that I am 
engaged in a job accident." and "Compared to other factories, I think this factory is more dangerous."

\section{Safety Outcome Scale.}

The scale is develop by Neal and colleagues (2000). The Turkısh translation of the scale is done by Dursun (2011)with the reliability of.93. The scale includes 6 items with 5 point Likert-type from totally disagree to totally agree. The three items of the scale measure safety participation such as "I put more effort to improve workplace safety" and 3 items measure safety compliance such as "I use appropriate safety procedures while doing my job." are used.

\section{Trust Scale.}

Because of the lack of questionnaires in the literature that measure the level of trust of employees' to their leaders' compliance to safety, the questionnaire is developed by the researchers. In the scale, there are five items with 5 point Likert-type from totally disagree to totally agree. The example item is "My manager is closely interested in my workplace safety.".

\section{Demographic Information.}

The demographic information questionnaire is specifically developed to measure work and safety history of the participants. It includes questions about age, gender, level of education, work area and history of safety related incidents and near mises.

After getting approval from ethical committee, the survey were distributed to blue-collar workers by the Human Resources Manager of the Company. During the shift changes, informed consent was given to all participants. After that, they completed the survey in approximately 30 minutes. After the completion of the survey, participants took debriefing form at the presence of the researchers.

\section{Results}

We first investigated descriptive statistics (mean, standard deviations, Cronbach Alphas of variables). The results of the analysis regarding descriptive statistics were presented in Tble 1. Table 1 demonstrates means, standard deviations, Cronbach Alphas and correlations of variables. The scores of means and standard deviations of variables were listed as for Safety climate $(\mathrm{M}=$ $3.50, \mathrm{SD}=.78)$, transformational leadership $(\mathrm{M}=2.89, \mathrm{SD}$ $=.91)$, transactional leadership $(M=3.4, S D=1.00)$, safety compliance $(M=3.46, S D=1.17)$, safety participation $(M=3.39$, $S D=1.16)$ and trust $(M=2.93, S D=1.03)$, respectively.

The internal consistency reliability of the safety climate scale was .66. The questions of leadership were divided into transformational and transactional leadership, and then their reliability scores were calculated separately. The reliability of transformational leadership was high (.90), whereas for transactional leadership it was low $(r=.52)$. Moreover, the reliability of safety compliance (.88), safety participation (.86), and trust to leaders commitment to safety (.92) was found to be high.
Table I: Descriptive Statistics and Correlations among Variables

\begin{tabular}{|cccccc|cc|c|}
\hline Variable & M & SD & 1 & 2 & 3 & 4 & 5 & 6 \\
\hline $\begin{array}{c}\text { Safety } \\
\text { Climate }\end{array}$ & $\begin{array}{c}3.5 \\
0\end{array}$ & .78 & $(.66)$ & & & & \\
\hline $\begin{array}{c}\text { Transfor- } \\
\text { mational }\end{array}$ & $\begin{array}{c}2.8 \\
9\end{array}$ & .91 & $.41^{* *}$ & $(.90)$ & & & \\
\hline $\begin{array}{c}\text { Transac- } \\
\text { tional } \\
\text { Leader- } \\
\text { ship }\end{array}$ & $\begin{array}{c}3.4 \\
0\end{array}$ & 1.00 & $.84^{* *}$ & $.39^{* *}$ & $(.52)$ & & \\
\hline $\begin{array}{c}\text { Safety } \\
\text { Participa- } \\
\text { tion }\end{array}$ & $\begin{array}{c}3.4 \\
6\end{array}$ & 1.17 & $.24^{*}$ & $.42^{* *}$ & $.26^{* *}$ & $(.86)$ & \\
\hline $\begin{array}{c}\text { Safety } \\
\text { Compli- } \\
\text { ance }\end{array}$ & $\begin{array}{c}3.3 \\
9\end{array}$ & 1.16 & $.28^{* *}$ & $.25^{*}$ & $.29^{* *}$ & $.72^{* *}$ & $(.88$ & \\
\hline $\begin{array}{c}\text { Trust to } \\
\text { leaders' } \\
\text { commit- } \\
\text { ment to } \\
\text { safety }\end{array}$ & 2.9 & 1.03 & $.24^{*}$ & $.62^{* *}$ & $.32^{* *}$ & $.45^{* *}$ & $.44^{*}$ & $(92)$ \\
\hline
\end{tabular}

Descriptive statistics showed that $30 \%$ of the workers had accident at least onece a year and $49.5 \%$ did not have any near misses. Of the remaining $50.5 \%, 29.7 \%$ had near misses at least once a year, $10.9 \%$ once every six moth, $3 \%$ had once every three months and finally, $7.3 \%$ had near misses more than five times a year. Near misses had low to medium significant correlations with the study variables but not with the safety climate and transactional leadership. Trust in leader and safety compliance was moderately correlated with experiencing accident at work.

Hypothesis Testing: Hypothesis 1 stated that transformational leadership has stronger relationship with safety climate than transactional leadership. The results did not support our hypothesis. Although, both transformational and transactional leadership were significantly related to safety climate, the result indicated that transactional leadership was strongly associated with safety climate $(r=.84, p<.01)$ compared to transformational leadership $(r=.41, p<.01)$.

Hypothesis 2 stated that transformational leadership style is strongly related to safety participation, whereas transactional leadership is strongly related to compliance. The results supported our hypothesis. Firstly, the significant relationship between transformational leadership and safety participation was detected $(r=.42, p<.01)$ while the relationship between transformational leadership and safety participation was stronger compared totransformational leadership and safety compliance $(r=.25, p<.05)$. Secondly, the significant relationships were observed between transactional leadership and both safety participation and safety compliance, yet the association between transactional leadership and safety compliance $(r=.29, p<.01)$ was stronger than the association between transactional 
leadership and safety participation $(r=.26, p<.01)$.

Hypothesis 3 stated that perceived safety climate predicts both safety participation and safety compliance. The results partially supported our hypothesis. It was examined that both safety compliance and safety participation were significantly related to safety climate; however, safety compliance had stronger correlation with safety climate $(r=.28, p<.01)$ compared to safety participation $(r=.24, p<.05)$. Hypothesis 4 pointed out that there will be significant effects of trust on safety outcomes. The findings also supported our hypothesis. Trust was significantly related to both safety compliance $(r=.44, p<.01)$ and safety participation $(r=.45, p<.01)$. Hypothesis 5: Transformational leadership will be strongly associated with trust to leaders' commitment to safety than transactional leadership. Our hypothesis was supported. Although both leadership styles significantly related to trust, transformational leadership was more strongly associated with trust $(r=.62, p<.001)$ compared to transactional leadership $(r=.32, p<.01)$.

The results of research question related to the relationship of leadership style and safety climate revealed that transactional leadership with safety climate had stronger relationship $(r=.81$, $p<.001)$ than the transformational style with safety climate $(r=.41, p<.001)$.

Hypothesis 6 stated that transformational leadership style is positively correlated with safety participation with respect to mediating effects of safety climate and trust in leaders' commitment to safety. Transactional leadership is associated with safety compliance with respect to mediating effects of safety climate and trust in leaders' commitment to safety.

Our meditational hypothesis was not supported with regard to the relationship between transactional leadership and safety compliance. The regression of safety compliance total scores on transactional leadership scores, ignoring the mediator (safety climate), was significant $(\beta=.27, t(99)=2.28, p<.05)$. The regression of safety compliance total scores on the mediator (safety climate) was also significant $(\beta=.42, t(99)=2.94, p$ $<.05)$. The regression of safety compliance scores on safety climate, controlling for transactional score, was not significant, ( $\beta$ $=.09, \mathrm{t}(99)=.35, \mathrm{p}>.05)$. Then, controlling for the mediator (safety climate), transactional leadership was not significant predictor of safety compliance $(\beta=.21, t(99)=1.03, p>.05)$. However, the path coefficient between safety climate and safety compliance became non significant. Therefore, the strong relationship between the transactional leadership and safety climate masked the relationship between safety climate and safety compliance.

The full mediating effect of trust on the relationship between transactional leadership and safety compliance was found. The regression of safety compliance total scores on transactional scores was significant $(\beta=.27, \mathrm{t}(99)=2.28, \mathrm{p}<.05)$. The regression of safety compliance total scores on the mediator (trust to the leaders commitment to the safety) was also significant $(\beta=.50, t(99)=4.87, p<.05)$. Controlling for transactional leadership, the regression of safety compliance scores on trust was also significant $(\beta=.49, t(99)=3.76, p$
$<.05)$. However, controlling for the mediator (trust), transactional leadership was not significant predictor of safety compliance $(\beta=.22, t(99)=1.95, p>.05)$. Bootstrap analysis also supported the full mediation.

There is also a mediating effect of trust on the relationship between transformational leadership and safety participation. The regression of safety participation on transformational total score was significant $(\beta=.48, t(99)=3.83, p<.05)$. Trust was a significant predictor of safety participation $(\beta=.50, t(99)=5.02$, $p<.05)$. Controlling for transformational leadership, the regression of safety participation on trust was significant $(\beta=.33, t(99)$ $=2.58, p<.05$ ) while controlling for trust, transformational leadership was not a significant predictor of safety participation ( $\beta$ $=.26, \mathrm{t}(99)=1.78, \mathrm{p}>.05)$. Bootstrap analysis also confirmed the full mediation in the relationship.

On the other hand, our hypothesis, that is, there is mediating effect of safety climate on the relationship between transformational leadership and safety participation, was not supported. The regression of safety participation on transformational leadership was significant $(\beta=.48, t(99)=3.82$, $p<.01)$. The regression of safety participation on safety climate was also significant $(\beta=.36, t(99)=2.53, p<.05)$. Controlling for transformational leadership, the regression of safety participation on safety climate was not significant $(\beta=08, t(99)=$ $86, p>.05)$. Then, controlling for the mediator (safety climate), transformational leadership was significant predictor of safety participation $(\beta=.38, \mathrm{t}(99)=3.87, \mathrm{p}<.05)$. Probably the strong relationship between transformational leadership and safety climate masked the mediating effect.

As a summary, we can say that trust mediated both the relationship between both kind of leadership on both kind of safety behaviors, but safety climate did not mediate the relationship between both leadership styles and both kind of safety behavior due to the strong correlation between leadership styles and safety climate. Strong leadership is suppressing the effect of safety climate safety behavior relationship.

\section{Discussion}

It is clearly obvious that, the findings presented in the current study have important implication for both literature and organizations.

Hypothesis 1 stated that Transformational leadership style is strongly related to safety participation and hypothesis 2 stated that transactional leadership is strongly related to safety compliance. The results confirmed our both hypothesis. The leadership style of the leaders affects safety outcomes in the organizations. It was found that employees in the organizations tend to comply with their safety by obeying safety rules when their leaders are high in transactional style. Employees with highly transformational leaders are found to be significantly 
participative to safety related events. In the current study, transactional leadership also found to be significantly related both of the safety outcomes. This might be because of the higher level of transactional leadership in the organization. Further, it was found that transactional -compliance link was stronger than transformational-compliance.

This finding is consistent with the literature. Since transactional leaders set performance goals and reward employees for the correct behavior and punish for the wrong one, it is natural that compliance will have stronger relationship with the MBEA type of transactional style than the transformational one. The week relation between participation and transactional style shows that to motivate employees beyond the call of duty, some form of inspirational motivation and other aspects of transformational leadership is needed. To make changes and suggest improvements related to safety are all parts of safety participation and this can be achieved by those whose need portfolios changed due to the characteristics of the

transformational leaders. Studies show the impact of leader behavior on innovation (see for example, Weng, Huang, Chen, \& Chang, 2015) as well as leader's ability to create an innovative climate in organizations. There is a need to utilize transformational style to improve the safety practices of the organizations with their useful suggestions. Probably these suggestions will be related to innovative ideas.

Hypothesis 3 stated that Perceived safety climate predicts both safety participation and safety compliance. It was found in the present study that safety related outcomes are influenced from safety climate. Higher level of perceived safety climate will cause higher level of positive safety related outcomes especially safety compliance and participation. In the literature it was well established that safety climate is important determinate of safety behaviors, accidents and injuries (Zohar, Huang, Lee, \& Robertson, 2014). For example Probost (2015) found that positive organizational climate reduces the underreporting of the injuries when accident happens. However safety climate-compliance relationship is stronger than safety climate-participation relationship. This may be mostly explained by Zohar, Huang, lee, \& Robertson's (2015) study in which the extrinsic motivation was the mediator in the relationship between safety climate of the long-haul truck drivers' safety behaviors. Management attitude to safety was included in the safety climate questionnaire in which there was both reward and punishment for the compliance and non compliance. Zohar et al (2015) found that when the climate is strong in the organizations, intrinsic motivation was not the reason for safe behavior and it is only when safety climate is low, intrinsic motivation (engagement) takes place. Since safety participation mostly a citizenship behavior, it has more intrinsic aspect in it.

Hypothesis 4 stated that there will be significant effects of trust on safety outcomes. In the literature, trust in leader was well established for the positive outcomes for individual and organizations (see Kasnakoğlu, 2013 for full coverage of the study). As mentioned before, there is little research regarding the trust as defined in this study and its mediating role. Firstly, higher level of trust is strongly associated with higher level of safety related outcomes. It is found that employees who have higher level of trust to their leaders' commitment to safety are more likely to commit to safety rules and participate to safety related events. This is consistent with the literature that trust in the leader result in both task and citizenship behavior. For example Dirks and Ferrin (2002) and Colquitt, Scot, and La Pine (2007), found that trust in leaders are most strongly related to citizenship and a lesser degree with task performance. In the present study, trust in leader was related to safety compliance and safety behavior to a same degree. Although safety participation is kind of citizenship behavior in the present study, the same degree of relationship with compliance might be due to the fact that trust was related to safety.

Hypothesis five states that "Transformational leadership will be strongly associated with trust to leaders' commitment to safety than transactional leadership". It was also found that transformational leadership was strongly related to trust than transactional leadership. This is consistent with the literature because employees trust leaders who do more than engage in day to day performance of the workers because they know their leaders capabilities and also they feel safe when they are with those leaders. Schaubroeck, Lam, and Peng (2011) found that transformational leadership was closely related to trust. Transactional leadership also had significant but lower correlation with trust in leader. It is understandable that the relationship is lower than the transformational style and trust relationship as explained above. Although it is inconsistent with some of the previous findings (eg Tremblay, 2010), there was a significant correlation between the transactional style and trust relationship in the present study. This might be related to measuring trust in relation with safety. Active style of transactional leadership might be making people feal good about their leader with regard to safety as they know that everything will be okay even without their involvement due to the particular leadership style.

In the current study, the research question asked if the transformational leadership would predict higher level of safety climate in the organizations than he transactional leaders. It was found that leaders who have higher level of transactional leadership had a larger impact on the safety climate of the organizations. Although transformational leadership also had positive relationship with the safety climate, its relation was weaker. This result shows that first it is important to establish baseline by some form of especially contingent reward and MBEA type of transactional style and further to maintain the positive climate, there is a need to add to the leadership style the transformational style. Therefore it is important to show fullrange leadership as Bass, Avolio, Jung, Berson (2003) suggested. This is consistent with a study by Quintana, Park, \& Cabrera (2015) in which they found that both transformational and contingent reward form of leadership styles are related to 
various employee and organizational outcomes. To increase positive safety climate in the organizations, it might be effective to choose transactional leadership style as well as some form of transformational style.

Although it was hypothesized (hypothesis 6), safety climate did not mediate the relationship between leadership styles and safety behaviors. Although the correlations were correct for the meditational purposes, the correlations between leadership and safety behaviors were stronger than the climate and safety behaviors correlation. The correlations between trust and safety behaviors were stronger than the safety climate and safety behavior correlations. Therefore, in case of safety climate, strong correlation between leadership styles and respective safety behaviors masked the relationship between climate and safety behavior relationships. Direct effects were stronger than the indirect effects. As for the trust due to a strong correlation between trust and independent and dependent variables crystallized the meditational role of the trust. The explanation might be that if you have appropriate leadership, employees show compliance or participation depending on the prevailing leadership style.

Strengths, limitations, practical implications for the managers and agenda for future research

This study is the one first examine the meditational mechanisms of leadership styles and safety behaviors. Also looked at the relationship between safety behaviors in terms of compliance and participation while examining the relationship between trust and safety behaviors. In a way the present study covered the complex relationship between leadership, safety climate safety behaviors and trust in leaders's commitment to employee's safety. Additionally, the study was a medium to develop a new scale of trust with a high level of reliability. Furthermore, the local literature is lack of scientific testing the relationship between leadership and safety behavior and there is a dearth of studies in this regard. Although State Statistical Institute (TÜIK) and Occupational Health and Safety Administration (ISGÜM) keeps some reports of safety, rarely they ask near misses as far as we know.

One of the most important limitations of the present study is the small sample size due to the difficulty of conducting surveys with hose who are working in safety critical oraganizaitons. There were many factors contributing to this end. First of all, these establishments are having continuous manufacturing. Therefore it was difficult to communicate with workers. Secondly, some percent of the workers did not even finish high school in most of the manufacturing organizations. Therefore, it is very difficult to collect data from surveys. Thirdly, people in the small towns may have difficulty expressing their feelings toward their working place especially in those places there is scarcity of employment. They may feel that they should be thankful rather than being critical. Another limitation of the current study is the scales in use. Although there were well established scales regarding the leadership styles and safety climate, due to the length of the scale and difficulty of collecting information from lenthy surveys with these types of workers, we had to shorten the scales. Therefore we have chosen scales as short of possible. As far as we see, the generalizability of the results to other organizations and workers are limited as only one type of organization used.

Due to the small sample size, the structural equation modeling could not be utilized as it give us a better view of multiple dependent, independent and mediator variables. In addition to that, we did not utilize multi level causal modeling as we have individual level and unit level level variables like leadership style and safety climate. Future studies using large sample sizes may utilize not only self report but also others reports of safety behaviors, both compliance and participation.

Table II: The Regression Analysis of Mediation Using a 3-Step Procedure; Safety Climate and Trust as Mediators of Leadership Styles and Safety Outcomes.

\begin{tabular}{|ll|l|}
\hline & $\beta$ & Mediator \\
\hline Step 1 & $.48^{*}$ & \\
Transformational-Participation & .20 & \\
Transformational-Compliance & .13 & \\
Transactional-Participation & $.27^{\star}$ & \\
Transactional-Compliance & & \\
Step 2 & $.36^{*}$ & \\
Climate-Participation & $.42^{*}$ & \\
Climate-Compliance & $.50^{*}$ & \\
Trust-Participation & $.50^{*}$ & \\
Trust-Compliance & -.06 & $.48^{\star}$ \\
Step 3 & .09 & .20 \\
Transformational-Climate-Participation & $.33^{*}$ & .26 \\
Transformational-Climate-Compliance & $.49^{\star}$ & -.11 \\
Transformational-Trust-Participation & -.06 & .17 \\
Transformational-Trust-Compliance & .09 & .21 \\
Transactional-Climate-Participation & $.33^{*}$ & .10 \\
Transactional-Climate-Compliance & $.49^{*}$ & .22 \\
Transactional--Trust-Participation & & \\
Transactional-Trust-Compliance &
\end{tabular}

\section{References}

1. 1.9 Million Workers Died in Workplace Accidents in Turkey Since 1992 (2015, March 10). Retrieved from http://www.aydinlikdaily.com/agenda/19-millionworkers-died-in-workplace-accidents-in-turkey-since-1992-h305.html

2. Bass, B.M., Avolio, B.J., Jung, D.I., \& Berson, Y. (2003). Predicting unit performance by assessing transformational and transactional leadership. Journal of Applied Psychology, 88(2), 207-218.

3. Braun, S., Peus, C., Weisweiler, S., \& Frey, D. (2013). Transformational leadership, job satisfaction, and team performance: A multilevel mediation model of trust. Leadership Quarterly, 24, 270-283.

4. Burke, C.S., Sims, D.E., Lazzara, E.H., \& Salas, E. (2007). Trust in leadership: A multi-level review and integration. The Leadership Quarterly, 18, 606-632.

5. Burns C., Mearns K., \& McGeorge P. (2006). Explicit and implicit trust within safety culture. Risk Analysis, 26(5), 1139-1150.

6. Carrillo-Castrillo, J.A., Rubio-Romero, J.C., \& Onieva, L. (2013). Causation of severe and fatal accidents in the manufacturing sector. International Journal of Occupational Safety and Ergonomics (JOSE), 19(3), 423- 434.

7. Cavazotte, F.S.C.N., Duarte, C.J.P., \& Gobbo, A.M.C. (2013). Authentic leader, safe work: the influence of leadership on safety performance. Brazilian Business Review, 10(2), 95-119.

8. Chia-Huei, W., \& Zhen, W. (2015). How transformational leadership shapes proactivity: The mediating role of positive affective tone and the moderating role of team task variety. Group Dynamics: Theory, Research, and Practice, 19(3), 137-151.

9. Christian, M.S., Bradley, J.C., Wallace, J.C., \& Burke, M.J. (2009). Workplace safety: A meta-analysis of the roles of person and situation factors. Journal of Applied Psychology, 94, 1103-1127.

10. Clarke, S. (2006). The relationship between safety climate and safety performance: A meta analytic review. Journal of Occupational Health Psychology, 11(4), 315- 327.

11. Clarke, S. (2013). Safety leadership: A meta-analytic review of transformational and transactional leadership styles as antecedents of safety behaviours. Journal of Occupational and Organizational Psychology, 86, 2249.

12. Conchie, S., Donald, I., \& Taylor, P.J. (2006). Trust: missing piece(s) in the safety puzzle. Risk Analysis, 26(5), 1097-1104.

13. Conchie, S., \& Donald, I.J. (2008). The functions and development of safety-specific trust and distrust. Safety Science. 46(1), 92-103. 
14. Colquitt, J.A., Scott, B.A., \& LePine, J.A. (2007). Trust, trustworthiness, and trust propensity: A meta-analytic test of their unique relationships with risk taking and job performance. The Journal of Applied Psychology, 92(4), 909927. doi:10.1037/0021-9010.92.4.909

15. Dirks, K.T., \& Ferrin, D.L. (2002). Trust in leadership: Meta-analytic findings and implications for research and practice. Journal of Applied Psychology, 87, 611-628.

16. Ferjencik, M., \& Slovackova, I. (2014). Trust managers and respect workmen: What does it mean to be competent in caring about safety? Journal of Loss Prevention in the Process Industries, 32, 95-108.

17. Fugas, C.S., Melia, J.L., \& Silva, S.A. (2011). The 'is' and the 'ought': How do perceived social norms influence safety behaviors at work? Journal of Occupational Health Psychology, 16(1), 67-79.

18. Fung, I.W.H., Lee, Y.Y., Tam, V.W.Y., \& Fung, H.W. (2014). A feasibility study of introducing chin straps of safety helmets as a statutory requirement in Hong Kong construction industry. Safety Science, 65, 70-78.

19. Gravan, T.N., \& O' Brien, F. (2001). An investigation into the relationship between safety climate and safety behaviors in Irish organizations. Irish Journal of Management, 22, 141-70.

20. Hoffmeister, K., Gibbons, A.M., Johnson, S.K., Cigularov, K.P., Chen, P.Y., Rosecrance, J.C. (2014). The differential effects of transformational leadership facets on employee safety. Safety Science, 62, 68-78.

21. International Labour Organization (2014). ILO introductory report: Global trends and challenges on occupational safety and health. Retrieved from http://www.ilo.org/global/topics/safety-and-health-at-work/ lang- en/index.htm

22. International Labor Office (2012). Safety and health at work. Retrieved from ILO Web site, http://www.ilo.org/global/topics/safety-and-health-at-work/lang-de/index.htm İş Sağlığı ve Güvenliği Enstitüsü Müdürlüğü (ISGUM). (n.d.). İş Güvenliği Bölümü. Retrieved from http://www.isgum.gov.tr/ AramaSonuclari.aspx?lnk=99

23. Jung, D.I., \& Avolio, B.J. (2000). Opening the black box: An experimental investigation of the mediating effects of trust and value congruence on transformational and transactional leadership. Journal of Organizational Behaviour, 21, 949-964.

24. James, L.A., \& James, L.R. (1989). Integrating work environment perceptions: Explorations into the meaning of meaning. Journal of Applied Psychology, 74, 739 -751. doi:10.1037/0021-9010.74.5.739

25. Kapp, E.A. (2012). The influence of supervisor leadership practices and perceived group safety climate on employee safety performance. Safety Science, 50, 1119-1124.

26. Kelloway, E. K., Mullen, J., \& Francis, L. (2006). Divergent effects of transformational and passive leadership on employee safety. Journal of Occupational Health Psychology, 11, 76-86. doi:10.1037/1076-8998.11.1.76

27. Krafft, P., Engelbrecht, A., \& Theron, C. (2004). The influence of transformational and transactional leadership on dyadic trust relationships through perceptions of fairness. SA Journal of Industrial Psychology, 30(1), 10-18.

28. Larsson, S., \& Torner, A.P.M. (2008). Psychological climate and safety in the construction industry-mediated influence on safety behavior. Safety Science, 46 (3), 405-412.

29. Luria, G. (2010). The social aspects of safety management: Trust and safety climate. Accident Analysis and Prevention, 42, 1288- 1295.

30. McAllister, D.J. (1995). Affect- and cognition-based trust as foundations for interpersonal cooperation in organizations. Academy of Management Journal, 38(1), 24-59.

31. Mullen, J., Kelloway, E.K., \& Teed, M. (2011). Inconsistent style of leadership as a predictor of safety behavior. Work \& Stress, 25(1), 41-54.

32. Nahrgang, J.D., Morgeson, F.P., \& Hofmann, D.A. (2008). A meta-analytic investigation of individual and contextual influences on workplace safety, satisfaction, and well-being. Paper presented at the Society for Industrial and Organizational Psychology, San Francisco.

33. Nielsen, M.B., Mearns, K., Matthiesen, S.B., \& Eid, J. (2011). Using the job demands-resources model to investigate risk perception, safety climate and job satisfaction in safety critical organizations. Scandinavian Journal of Psychology, 52(5), 465-475. doi:10.1111/j.1467-9450.2011.00885.x

34. Occupational Safety \& Health Administration (OSHA). (n.d.). Business case for safety and health. Retrieved from https://www.osha.gov/dcsp/products/ topics/businesscase/benefits.html

35. Probst, T.M. (2015). Organizational safety climate and supervisor safety enforcement: Multilevel explorations of the causes of accident underreporting. Journal of Applied Psychology. Advance online publication. doi: http:// dx.doi.org/10.1037/a0039195

36. Quintana, T., Park, S., \& Cabrera, Y. (2015). Assessing the effects of leadership styles on employees' outcomes in international luxury hotels. Journal of Business Ethics, 129(2), 469-489. doi:10.1007/s10551-014-2170

37. Sawacha, E., Naoum, S., \& Fong, D. (1999). Factors affecting safety performance on construction sites. International Journal of Project Management, 17(5), 309-315.

38. Seppänen, R., Blomqvist, K., \& Sundqvist, S. (2007). Measuring inter-organizational trust-a critical review of the empirical research in 1990-
2003. Industrial Marketing Management, 36, 249-265.

39. Schaubroeck, J., Lam, S.S.K., \& Peng, A.C. (2011). Cognition-based and affect-based trust as mediators of leader behavior influences on team performance. Journal of Applied Psychology, 96(4), 863-871.

40. Shen, Y., Tuuli, M., Xia, B., Koh, T., \& Rowlinson, S. (2015). Toward a model for forming psychological safety climate in construction project management. International Journal of Project Management, 10, 223235.

41. Tharaldsen, J-E., Mearns, K., \& Knudsen, K. (2010). Perspectives on safety: The impact of group membership, work factors and trust on safety performance in UK and Norwegian drilling company employees. Safety Science, 48, 1062-72.

42. Törner, M. (2011). The "social-physiology" of safety. An integrative approach to understanding organisational psychological mechanisms behind safety performance. Safety Science, 49, 1262-1269.

43. Tremblay, M.A. (2010). Fairness perceptions and trust as mediators on the relationship between leadership style, unit commitment, and turnover intentions of Canadian Forces personnel. Military Psychology, 22(4), 510-523.

44. Turkey Statistics Institution (SI). (n.d.) Statistics news: SI 2013 Statistic results [Data file]. Available from SI Web site: http://www.tuik.gov.tr/ PreHaberBultenleri.do?id=16118.

45. Weng, R.H.; Huang, C.Y; Chen, L.M.; \& Chang, L.Y. (2015). Exploring the impact of transformational leadership on nurse innovation behaviour: $A$ cross-sectional study.

46. Journal of Nursing Management, 23(4), 427-439. Workplace accidents skyrocketing in Turkey (2015, May 5). Retrieved from http:// www.hurriyetdailynews.com/workplace-accidents-skyrocketing-in-turkeyaspx?pagelD=238\&nID=81989\&NewsCat ID $=347$

47. Yi-Feng Yang. (2014). Studies of transformational leadership: Evaluating two alternative models of trust and satisfaction. Psychological Reports, 114(3), 740-757.

48. Zacher, H., Pearce, L., Rooney, D., \& McKenna, B. (2014). Leaders' personal wisdom and leader-member exchange quality: The role of individualized consideration. Journal of Business Ethics, 121(2), 171-187. doi:10.1007/ s10551-013-1692-4.

49. Zhu, W., Newman, A., Miao, Q., \& Hooke, A. (2013). Revisiting the mediating role of trust in transformational leadership effects: Do different types of trust make a difference?. The Leadership Quarterly, 24, 94-105.

50. Zohar, D. (1980). Safety climate in industrial organizations: Theoretical and applied implications. Journal of Applied Psychology, 65(1), 96-102.

51. Zohar, D., Huang, Y., Lee, J., \& Robertson, M. (2014). A mediation model linking dispatcher leadership and work ownership with safety climate as predictors of truck driver safety performance. Accid. Anal. Prev., 62, 17-25.

52. Zohar, D., Huang, Y., Lee, J., \& Robertson, M.M. (2015). Testing extrinsix and intrinsic motivation as explanatory variables for the safety climate-safety performance relationship among haul truck drivers. Transportation Research Part F: Traffic Psychology and Behavior, 30, 84-96.

53. Zohar, D., \& Luria, G. (2003). Organizational meta-scripts as a source of high reliability: The case of an army armored brigade. Journal of Organizational Behavior, 24, 837-859.

54. Zohar, D., \& Luria, G. (2010). Group leaders as gatekeepers: Testing safety climate variations across levels of analysis. Applied Psychology, 59, 647-673. 